\title{
OPPORTUNITIES AND CHALLENGES FOR THE DEVELOPMENT OF YOUTH TALENT: A REPERCUSSION
}

\author{
Pallabi Devi \\ Research Scholar, Department of Sociology, Dibrugarh University, Assam, India
}

\begin{abstract}
For a developing country, the notion is that higher education is the platform of youth talent. As regards, the policymakers and Government initiatives can introduce and develop that the concept of the formal education process will be formulated for the talent ability. With the help of multidisciplinary subjects, youth have power, and are ready to develop their talent. With the best opportunity, youth would have been influenced by better work through talent. In the rapid growth of National income, the early stage should be responsible for this. The contribution of youth students for the development of the economy is the foremost responsible for a developed country. But poverty is the major obstacle for the development of the talent circle. The recent work attempts to understand the challenges and opportunities faced by the youth to show the talent in multiple areas or fields.
\end{abstract}

Key words: Development, youth, talent and poverty.

Cite this Article: Pallabi Devi, Opportunities and Challenges for the Development of Youth Talent: A Repercussion, International Journal of Management, 11(12), 2020, pp 531-535.

http://iaeme.com/Home/issue/IJM?Volume=11\&Issue=12

\section{INTRODUCTION}

Every human being has their talent in the existing society. Some extent, talent is called the innovation, re-innovation of objects, creativity and ability. It is measured by the existence of the object in the society to, the development approach, some talent search organisation used for nurturing talent. Acquisitive talent must contribute to the youth empowerment in our society. Youth is a power in any country to use the Nation-building process. Youth talent consists of personality development and social development of a person. Talent is that, to some extent, skill in any field. So skill development is the renowned figure of any area in social strata accommodated with unique in-build characteristics of people. One Nation is called a developed when the human resources developed as well. In that context, for the development of human resources, environment and technology also plays an important role. New Technological innovation of different sectors in a country focused on essential 
opportunities and creativity sign of youth. The talent search organization is full of human resources and need for power and some roles which are designed by different activities. Therefore talent is ascribed as well as achieved. On the other hand, society needs talented individuals to create a bright future of every State and Nation. Such areas are science, technology, and engineering, medicine to solve the problems of hunger, disease and destruction of the living environment. Art and culture, entertainment gives us enhancement and celebrates creativity.

Behavioural sciences, leadership and such organization, so that it gives us purpose justice and equality for all people. Ethical and moral science, philosophy and principles analysis give us how individuals and groups deal with the complex challenges of human existence. On the other hand, terminology like innovators, inventors, entrepreneurs, scholars, artists and leaders are needed to solve the socio-economic problem of society. Fulkerson\& Michael (1998) described the two perspectives of talent development. To upgrade the rigorously academic education curriculum but the extra-curricular activities are also available. The cognitive skill development can improve the talent upstairs for the youth. They point out the system of education must be changed and educational programs that recognise, develop and nurture talents in all our children of all academic levels, from primary level, Middle level and high school level nurturing and refining the skill.

Thapliyal (2013) has pointed out the use of ICT in higher education. Information and communication technology is a crucial driver of socio-economic change worldwide. 'Education for all' being one of the millennium development goals, social equity at all the levels of education is imperative. The contemporary challenges are to access equity and quality of higher education simultaneously. Hence ICT is demanding and as a way to promote educational change, improve the basic skills of learners, prepare them for the global economy and the information society as possible. Lee (2014), stated that the education hubs and talent development through the policymaking and implementation challenges. In the 1990s, the new tract of education process changed the social and traditional society.

\section{METHODS}

The present study is based on analytical methods and draws on data from secondary sources. It has collected from various sources like books, journals and reports.

To understand the opportunity and challenges towards the talent development in India.

\section{HINDRANCE FOR TALENT DEVELOPMENT}

Youth talent is gradually developed from day to day in a developing country like India. Administrative sections of society are also provided with some talent search organization and scopes to put forward some academic investigation. For the development of youth talent in society, Governments were more active to adopt such opportunities. The opportunities are sometimes more productive, and sometimes it has led to the advertisement policy only. The Ministry of Education has implemented the traits as creativity, morality and critical thinking for youth empowerment. The activities like sports, music, culture, creativity provoked the hidden talent of a person. To the extent the opportunities and motivations are somewhere did not get by the talented person. Regarding the issue of talent and opportunity to develop for youth empowerment is the necessity of society.

\section{From these necessities to fill up, the main limitations are-}

Uses of vernacular languages are one of the essential issues for the increasing talent hub of a developed country. The language problem is playing a vital role in the rural areas; it is entirely different from metro city and smart city to rural areas in India. Maximum people of 
Assam seem to use local language. In Assam, educational Institutions are also ruling to the Assamese and other local language systems. But in the era of globalization and transformation, English language is most important. However, they have their quality, but the language is sometimes hampered to youth development. Secondly, the lack of mentor; Mentor is like the importance of knowledge and support and guidance to provide from one generation of them. The nurture of talent demanded by the mentor is the main subject of informal and formal education. Education is as important as nurturing talent development.

The economic condition is responsible for the main challenges in the present era. As we know, now the developed country can become significant in an influential role in talent. There are various forums designed for the development of youth talent. The Global Innovation Index is the annual ranking process which is provided by the innovative ideas and knowledge from developed and developing countries. India has ranked $52^{\text {nd }}$ from all over the world. Hence it creates some major creative problems of Indian environment. The Government of India also provided some elegant chances for such talent improvement activities. Social, economic and political movements are also related to the challenges of youth talents. Thirdly, lack of good Infrastructure; in a developing country, the infrastructure problem is the main problem of talent enhancement. The political and social circumstances are the critical issues of intermediate situations. For music, sports and other talent improvement issues, the new technology has not arrived in the rural areas. Fourthly, lack of communication and advanced technology can be hampered to the talent search of a rural environment. For agriculture, the crop production and food processing process depend on old technology. New tools and technology have not come up in the village areas, enhanced lack of modern technology can hinder the rural food and crops processing process - the vital opportunity and challenges faced by the youth from the lack of proper education. In education, skill is more significant for increasing talent development. It is known that knowledge and technology continue to expand explosively in quantity and complexity and as our children and youth face ever more difficult personal, career and social challenges, the burden we expect education to bear only continues to increase. We must recognize the importance of knowledge and competence as well as the need to nurture talent, imagination, judgment and ethical conduct among all our young people".(Triffinger, 1998). Education, the essential requirement plays a horizontally and vertically significant indicator of the development of a person. Lack of technical knowledge is the main hindrance of talent development. Talent is such ideal for every child and every young follower. Mid of $19^{\text {th }}$ century time, the technical line is not spread all over in India. The educational institution is limited for talent searching basically agriculture, horticulture sericulture institute and technological institute. For the agricultural sector, there were some policies implemented by the Government of India. The producing knowledge system is not good from the other State or Nation. Higher education is challenging for historically weaker or marginalized sections of society. Historically remote area and marginalized sections of people have been facing some challenges in the higher education system in India. After the economic liberalization in India, the institution of education was greatly privatized and thus, the problems of the marginalized to have access to quality education also increased. Neo-liberalism prevailed in India since1990's. It has led to privatization of higher education and has made education being more market-oriented than a source for imparting knowledge. The difference between marginalized or less privileged section of the society regarding the terms of higher education has been increasing. Through the provisions of positive discrimination and economic support through scholarship or loans tried to achieve the necessary parity of equity. Hence equity has developed while on the other hand, inequity continues to be there in the society. With the public education system is changing to private, there are a lot of changes in the enrolment fees and other charges. Thus in society, rich people can afford to pay this fee, while the poor cannot. But all rich people are 
not interested in higher education while many lower-class families aspire and try to provide good education to their children. It is a challenge for those who are differently able and hubs of talent in our society. Differently, able youth is the hub of talent in our society.

The Indian education policy is different from developed country education policy. It is different from State to State. Therefore talent is based on various systems of education policy. In the context of Assam, a student becomes an expert to the artistic side, but the opportunity cannot be brought up by them. Therefore the education cannot be affordable for everyone. It has recognized the need for talent accomplishments in many areas that will be essential to human progress, the better quality of life and the enjoyment of leisure and survival of itself.

Technology can do anything which is not done in a general way. It is commonsense of knowledge. Regarding society, the perspective of technology can round everywhere.

The new technological era has been changing the rural and urban both of social and economic life would make memorable society. Social media and other technical opportunities would be more responsible for the talent search process in a rural and urban environment. Therefore it has also laid to the new era of society too much. For holistic development, both the formal and informal sectors must be equally significant in the industry and manufacturing companies.

Homemaker is the concept of every rural and urban household of Assam. Even the skill is the central theme of cooking, not measuring if he/she has talent in their capacity. The inner talent development is so not developed in a rural area. A good homemaker is called a housewife. It is to keep and develop a concept in our mind. So the dignity of labour is not understood by society.

Higher education is the way to transform knowledge and primarily related to the hub of talent acquisition. In the précising of the knowledge hub, the educational institutions are operating the 'time free' and 'space free' initiation for the talent improving system. In the system enhancing, the community colleges can be important too. Community colleges have some factors that are defining equal opportunity. Equal opportunity approaches are to define equal education through the distribution of opportunities. It also concerned such benefits as skills, knowledge, credentials and more indirectly levels of income, social status and others. So the equal opportunity among racial, sexual or regional groups is participation, choices and resources. Kauppinen (2012), has discussed academic capitalism as challenges for higher education in the local, national and global level. It is the relation between University and market commodities like industry. It directs the relations between Universities and their social environment. Thus academic capitalism is a new diverse phenomenon as the influence of neo-liberalism and calls for accountability, assessment and rankings. From the perspective of the social world, the main functions of academic capitalism are together with the training of a skilled workforce is the transformation of profitable market commodities.

\section{CONCLUSION}

Nurturing talent is powerful for holistic development in developing countries like India. Therefore the management system should be playing the right way as much as possible in India. But a specific curriculum and instruction cannot identify all talent of youth. A perfect platform in every corner of India is vital for them, and hence holistic development could be possible sincerely. The traditional ways of approaches and new understandings can be changed through the present global education system. Therefore, talent identification and redevelopment of youth ideas and creativity are also crucial for the youth development in India. 
Pallabi Devi

\section{REFERENCES}

[1] Terffinger. J, Donald. (1998). From Gifted education to Programming for Talent Development: The Phi Delta Kappan, Vol-79

[2] Roberts Link Julia.(2008) A 'Must' for a Promising Future: The Phi Delta Kappan, Vol-89

[3] Fulkerson, Jan and Horvich, Michael.(1998). Talent Development-Two perspectives: The Phi Delta Kappan, Vol-79

[4] Kerr and Kerr, Et.al. (2016).Global Talent Flows: The Journal of Economic Perspectives.Vol30 .

[5] Kauppinen, Ilkka. (2012).Towards transnational academic capitalism: Higher education, Vol64

[6] Lee, T. Jack, (2014). Education hubs and Talent Development: Policy making and Implementation Challenges. Higher Education, Vol-6. 